09,12

\title{
Оптические свойства металлодиэлектрических структур на основе фотонно-кристаллических опаловых матриц*
}

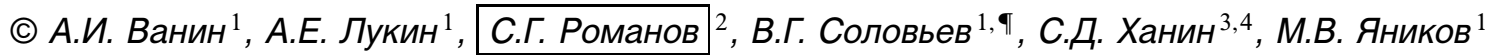 \\ ${ }^{1}$ Псковский государственный университет, \\ Псков, Россия \\ ${ }^{2}$ Физико-технический институт им. А.Ф. Иофффе РАН, \\ Санкт-Петербург, Россия \\ ${ }^{3}$ Российский государственный педагогический университет им. А.И. Герцена, \\ Санкт-Петербург, Россия \\ ${ }^{4}$ Военная академия связи им. Маршала Советского Союза С.М. Буденного, \\ Санкт-Петербург, Россия \\ E-mail: solovyev_v55@mail.ru
}

Исследованы оптические свойства новых металлодиэлектрических нанокомпозиционных материалов на основе опаловых матриц. Положение оптических резонансов нанокомпозитов, полученных введением серебра в матрицу опала методом электротермодиффузии, объяснено брэгговской дифракцией, а асимметричная форма резонансных кривых - резонансом Фано.

Обнаружено аномальное пропускание и поглощение света гибридными плазмонно-фотонными слоистыми гетероструктурами, связанное, по-видимому, с возбуждением поверхностных плазмон-поляритонов, распространяющихся вдоль границ раздела „металл-диэлектрик“.

Работа выполнена при поддержке Министерства образования и науки Российской Федерации (НИР № 576 в рамках базовой части государственного задания в сфере научной деятельности по заданию № 2014/700 за 2014 г.).

DOI: 10.21883/FTT.2018.04.45691.06D

\section{1. Введение}

В последние десятилетия особую актуальность приобрели исследования фотонных кристаллов (ФК), которые используются для управления потоками электромагнитного (ЭМ) излучения. В качестве модельных объектов при исследовании оптических свойств ФК, могут выступать как синтетические опаловые матрицы [1], состоящие из одинаковых по размеру субмикронных сфер из $\mathrm{SiO}_{2}$, упакованных в гранецентрированную кубическую структуру, способную играть роль трехмерной дифракционной решетки для видимого света, так и опалоподобные пленки, образованные глобулами из полимерного материала.

Фотонно-энергетическую структуру (ФЭС) подобных систем, определяющую их оптические свойства, можно изменять, создавая на их основе пространственнонеоднородные нанокомпозиционные материалы. В их число входят гибридные плазмонно-фотонные металлодиэлектрические структуры, дающие возможность целенаправленно формировать оптический отклик систем, что значительно расширяет их функциональные возможности [2-6]. При этом физика процессов, вызывающих модификацию исходной ФЭС, определяется как дизайном создаваемой гетероструктуры, так и методом

\footnotetext{
* Доклад на XIV Международной конференции „Физика диэлектриков““, Санкт-Петербург, 29 мая-2 июня 2017 г.

Материалы симпозиума частично опубликованы в выпуске № 3 за 2018 г. журнала „Физика твердого тела“.
}

введения в опаловую матрицу различных веществ, а также их оптическими свойствами.

Цель настоящей работы заключалась в установлении физических закономерностей оптических явлений в двух типах металлодиэлектрических структур на основе фотонно-кристаллических опаловых матриц:

1) в нанокомпозиционных материалах $\mathrm{Ag} /$ опал на основе „массивных“ опаловых матриц, в которые серебро вводилось методом электротермодиффузии;

2) в слоистых металлодиэлектрических структурах $\mathrm{Ag} / \mathrm{SiO}_{2} / \mathrm{Ag} / \mathrm{ML} / \mathrm{Ag}$, полученных последовательным напылением металлических $(\mathrm{Ag})$ и диэлектрических $\left(\mathrm{SiO}_{2}\right)$ пленок на монослой (ML) опаловых глобул.

\section{2. Методика эксперимента}

Объектами исследования в настоящей работе служили „массивные“ образцы нанокомпозитов Ag/опал (рис. $1, a)$ и слоистые тонкопленочные гетероструктуры $\mathrm{Ag} / \mathrm{SiO}_{2} / \mathrm{Ag} / \mathrm{ML} / \mathrm{Ag}$ (рис. $1, b$ ).

Нанокомпозиты Ag/опал получены введением серебра в опаловую матрицу методом электротермодиффузии при значениях напряженности электрического поля $E=1.70-3.75 \mathrm{kV} / \mathrm{cm}$ и температурах $T=660-800 \mathrm{~K}$.

Для образцов $\mathrm{Ag} / \mathrm{SiO}_{2} / \mathrm{Ag} / \mathrm{ML} / \mathrm{Ag}$ (рис. $1, b$ ) нанесение пленочных покрытий на монослой (ML) опаловых глобул из полиметилметакрилата (ПММА) производилось методом магнетронного распыления на установке АТC ORION SERIES SPUTTERING SYSTEM. Отметим, что 

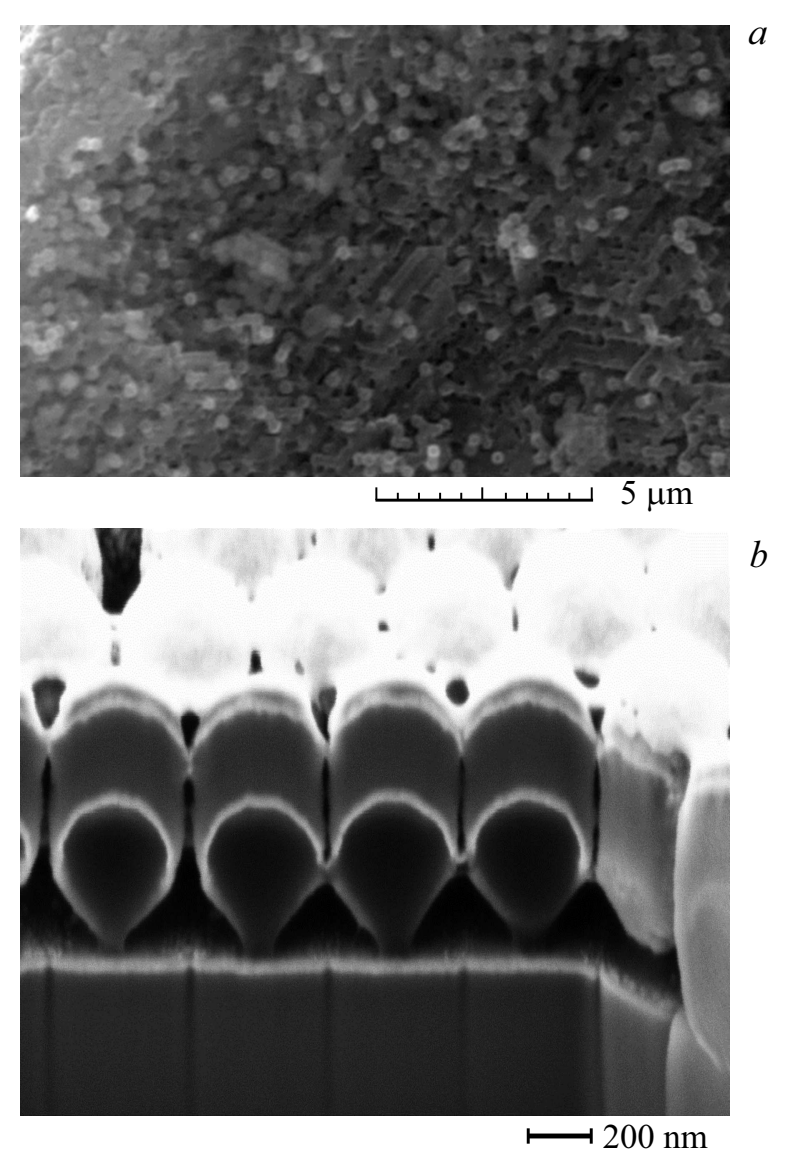

Рис. 1. Электронно-микроскопические изображения образцов $\mathrm{Ag} /$ ппал $(a)$ и $\mathrm{Ag} / \mathrm{SiO}_{2} / \mathrm{Ag} / \mathrm{ML} / \mathrm{Ag}(b)$.

наружная поверхность тонкого слоя металла (или диэлектрика), покрывающего опаловые глобулы, при этом сохраняет форму и пространственную периодичность, характерную для границы раздела между опаловой матрицей и этим слоем [7].

Оптические свойства полученных ФК исследовались методом брэгговской спектроскопии с угловым разрешением при помощи экспериментальных установок на базе спектрометров Ocean Optics QE65000 и USB650 Red Tide.

\section{3. Результаты и их обсуждение}

Введение серебра в опаловую матрицу методом электротермодиффузии существенным образом модифицирует спектры отражения образца (рис. 2). Сравнение спектров отражения исходной матрицы опала (рис. 2, кривые 1 и 3) и нанокомпозита $\mathrm{Ag} /$ опал (рис. 2, кривые 2 и 4) показывает, что введение серебра в матрицу опала приводит к длинноволновому сдвигу максимумов брэгговского отражения ФК при фиксированных значениях угла падения света. Этот эффект, неоднократно наблюдавшийся многими исследователями и ранее при введении различных веществ в опаловые матрицы, можно связать с увеличением эффективного показателя преломления системы при диспергировании в исходной матрице вещества-,,гостя“،

Из рис. 2 видно также, что в спектрах отражения матрицы-,хозяина“ и нанокомпозита $\mathrm{Ag} /$ опал наблюдается обычный коротковолновый сдвиг максимумов при увеличении угла падения. При этом угловая дисперсия брэгговского резонанса первого порядка в спектрах обоих типов (рис. 3) хорошо описывается известной формулой, которая следует из законов Вульфа-Брэгга и Снеллиуса:

$$
\lambda^{2}=4 a^{2} n^{2}-4 a^{2} \sin ^{2} \theta
$$

где $\theta-$ угол падения, $a=0.816-$ межплоскостное расстояние для плоскостей (111) ГЦК структуры опала, $D$ - диаметр сфер, $n$ - эффективный показатель преломления исследуемого фотонного кристалла.

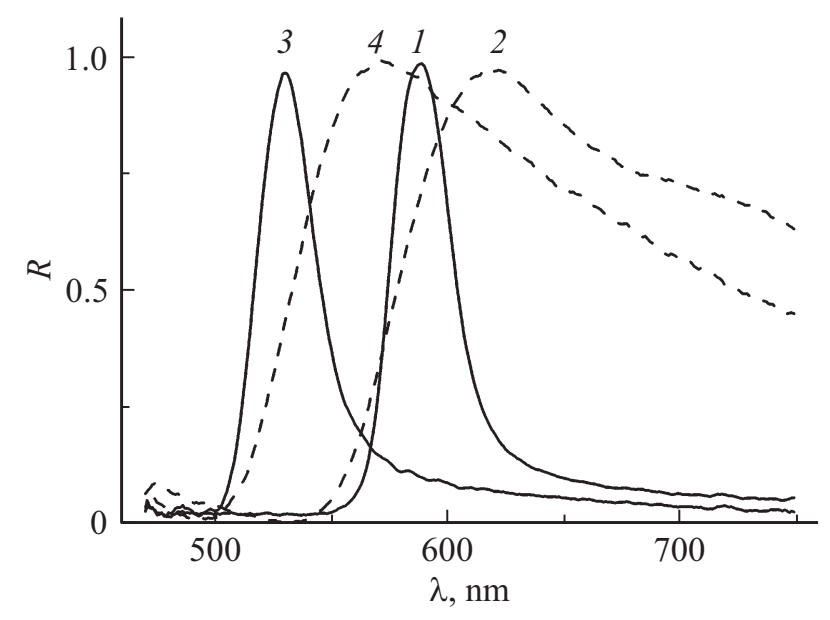

Рис. 2. Нормированные спектры отражения исходной матрицы опала $(1,3)$ и нанокомпозита $\mathrm{Ag} /$ опал $(2,4)$ при углах падения света $20^{\circ}(1,2)$ и $40^{\circ}(3,4)$.

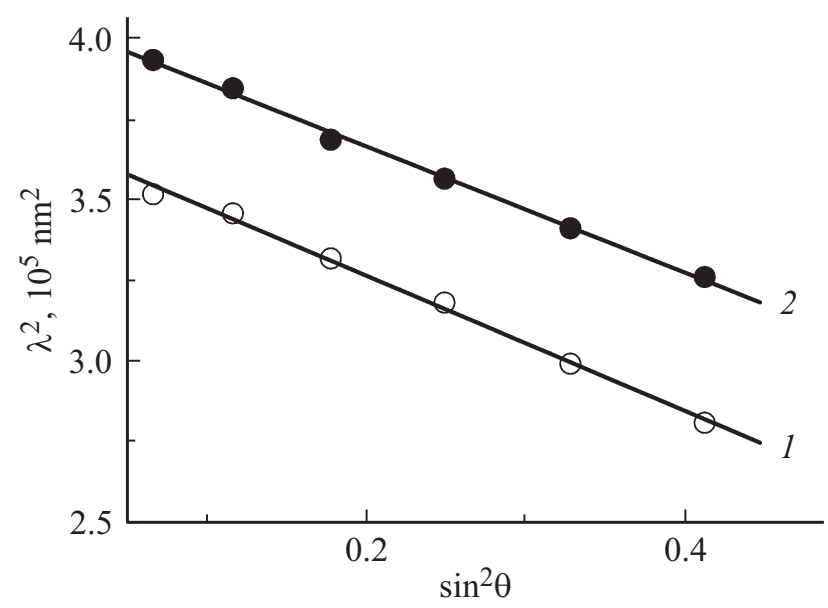

Рис. 3. Угловая дисперсия брэгговского резонанса первого порядка исходной матрицы опала (1) и нанокомпозита $\mathrm{Ag} /$ опал (2). 
Вместе с тем обращает на себя внимание ярко выраженная асимметрия широких полос в спектрах отражения нанокомпозита $\mathrm{Ag} /$ опал (рис. 2, кривые 2 и 4), существенно отличающихся от соответствующих кривых $R(\lambda)$ исходной опаловой матрицы (рис. 2, кривые 1 и 3$)$.

Подобный профиль характерен для резонанса Фано [8], который впервые наблюдался на брэгговских линиях в оптических спектрах чистых (без примесей) синтетических опалов авторами работ [9-11]. Как следует из сравнения кривых 2 и 4 с кривыми 1 и 3 (рис. 2), введение серебра в опаловую матрицу приводит к еще более яркому проявлению резонанса Фано, который может быть описан теоретически [6] на основе модельных представлений об интерференции двух волновых процессов. В данном случае в роли одного из них, по-видимому, выступает брэгговский дифракционный резонанс в ФК, a второй представляет собой излучение, рассеянное на случайных нарушениях структуры матрицы опала и неоднородностях (дендритах) в местах проникновения серебра в опаловую матрицу (рис. $1, a)$.

Спектры пропускания $T(\lambda)$ исследованных в работе тонкопленочных слоистых металлодиэлектрических структур при угле падения света $\theta=15^{\circ}$ представлены на рис. 4. Сравнение кривых 1 и 2 (рис. 4,a) показывает, что нанесение профилированной металлической пленки на монослой опаловых глобул приводит не только к ожидаемому общему уменьшению оптического пропускания образца, но также к появлению двух областей аномального пропускания (extraordinary transmission EОT) - вблизи 590 и $500 \mathrm{~nm}$. Как отмечалось в работе [5], возникновение указанных особенностей может быть связано с возбуждением поверхностных плазмонполяритонов (ППП) [12,13] на границах раздела профилированной металлической пленки с диэлектрическим монослоем глобул из ПММА и воздухом соответственно. Спектральное положение коротковолновых пиков на кривой 2 соответствует особенностям, наблюдаемым в оптических спектрах металлического серебра [12-14], связанным с его электронной зонной структурой. На рис. 4, $b$ (кривая 1 ) наглядно показаны относительные изменения спектра, обусловленные нанесением металлической пленки на монослой опаловых глобул.

Если последовательно с системой соединить оптический резонатор $\mathrm{Ag} / \mathrm{SiO}_{2} / \mathrm{Ag}$ с пиками пропускания при 395 и $760 \mathrm{~nm}$ (рис 4, a, кривая 3), то наблюдается дальнейшее уменьшение коэффициента пропускания рассматриваемой системы (рис. 4, $a$, кривая 4). Однако при этом происходит не только относительное увеличение аномального пропускания (ЕОТ), но и превращение максимумов пропускания резонатора (рис. 4, $a$, кривая 3) в максимумы поглощения (extraordinary absorption - EOA) гибридного плазмонно-фотонного кристалла (рис. 4, $b$, кривая 2). Этот экспериментальный результат дает основание предположить, что в гибридных плазмонно-фотонных кристаллах со сложной
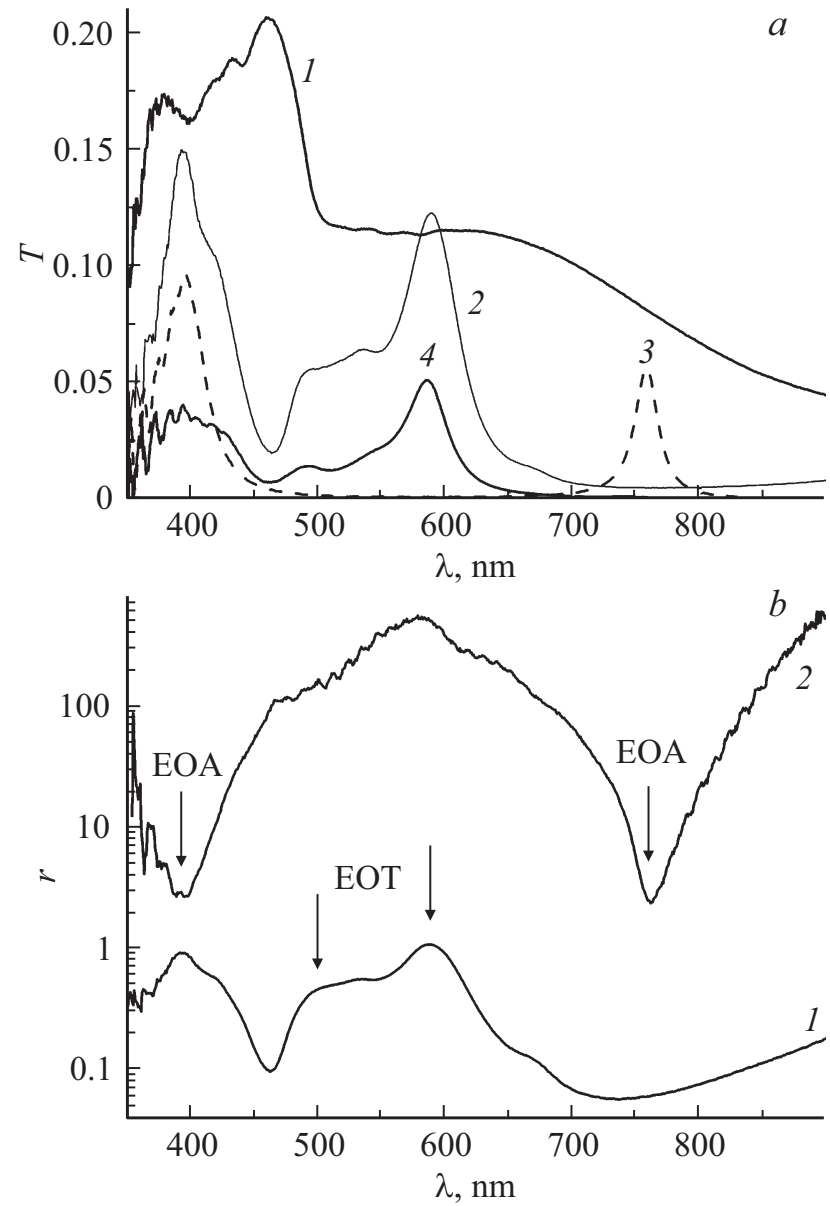

Рис. 4. a) Спектры пропускания монослоя опаловых глобул $\left(T_{1}(\lambda)\right.$, кривая 1$)$, плазмонно-фотонного кристалла $\mathrm{Ag} / \mathrm{ML} / \mathrm{Ag}$ $\left(T_{2}(\lambda)\right.$, кривая 2), резонатора $\mathrm{Ag} / \mathrm{SiO}_{2} / \mathrm{Ag}\left(T_{3}(\lambda)\right.$, кривая 3), гибридного плазмонно-фотонного кристалла $\mathrm{Ag} / \mathrm{SiO}_{2} / \mathrm{Ag} / \mathrm{ML} / \mathrm{Ag}$ $\left(T_{4}(\lambda)\right.$, кривая 4) при угле падения света $\left.\theta=15^{\circ} . b\right)$ Отношения $r_{1}=T_{2}(\lambda) / T_{1}(\lambda)$ (кривая 1) и $r_{2}=T_{4}(\lambda) /\left(T_{2}(\lambda) \times T_{3}(\lambda)\right)$ (кривая 2).

архитектурой возможно возбуждение ППП двух типов: „светлых“, отвечающих за аномальное пропускание, и „темных“, вызывающих аномальное поглощение.

\section{4. Заключение}

Таким образом, в работе показана возможность практической реализации двух различных подходов к созданию металлодиэлектрических композитов на основе опаловых матриц. Первый из них осуществляется посредством введения металла в матрицу опала методом электротермодиффузии, второй - с помощью последовательного напыления тонких слоев металла и диэлектрика на поверхность опаловых глобул.

В обоих случаях происходит существенная модификация фотонно-энергетической структуры исходной диэлектрической матрицы за счет гибридных взаимо- 
действий собственных фотонных мод и возбужденных в металле возмущений, природа которых различна.

Предложенные подходы к разработке архитектуры металлодиэлектрических структур на основе фотоннокристаллических опаловых матриц могут найти практическое применение в фотонике и наноплазмонике при создании оптических систем, управляющих потоками электромагнитного излучения.

Авторы признательны М.И. Самойловичу, В.И. Гербредеру, А.С. Огурцову, А.В. Цветкову, У. Пешелю и Д. Плоссу за предоставление образцов для исследования и помощь в проведении экспериментов.

\section{Список литературы}

[1] V.N. Astratov, V.N. Bogomolov, A.A. Kaplyanskii, A.V. Prokofiev, L.A. Samoilovich, S.M. Samoilovich, Yu.A. Vlasov. Il Nuovo Cimento 17D, 1349 (1995).

[2] V.S. Gorelik, L.I. Zlobina, V.A. Karavanskii, O.A. Troitskii, R.I. Chanieva. Inorg. Mater. 46, 862 (2010).

[3] S.G. Romanov, A. Korovin, A. Regensburger, U. Peschel. Adv. Mater. 23, 2515 (2011).

[4] V.L. Veisman, S.G. Romanov, V.G. Solovyev, M.V. Yanikov. Proc. X Int. Sci. and Practical Conf. „Environment. Technology. Resources“. Rēzekne, Latvia (2015). P. 230.

[5] A.V. Cvetkov, V.I. Gerbreders, S.D. Khanin, A.E. Lukin, A.S. Ogurcovs, S.G. Romanov, V.G. Solovyev, A.I. Vanin, M.V. Yanikov. Proc. XI Int. Sci. and Practical Conf. „Environment. Technology. Resources“. Rēzekne, Latvia (2017). P. 37.

[6] А.И. Ванин, В.Г. Соловьев. Сб. науч. тр. VI междунар. конф. по фотонике и информационной оптике. М., НИЯУ МИФИ (2017). С. 140.

[7] Н.О. Алексеева, В.Л. Вейсман, А.Е. Лукин, С.В. Панькова, В.Г. Соловьев, М.В. Яников. Нанотехника, 3 (31), 23 (2012).

[8] U. Fano. Phys. Rev. 124, 1866 (1961).

[9] M.V. Rybin, A.B. Khanikaev, M. Inoue, K.B. Samusev, M.J. Steel, G. Yushin, M.F. Limonov. Phys. Rev. Lett. 103, 023901 (2009).

[10] M.V. Rybin, A.B. Khanikaev, M. Inoue, A.K. Samusev, M.J. Steel, G. Yushin, M.F. Limonov. Photon. Nanostruct. Fundamentals and Appl. 8, 86 (2010).

[11] M.F. Limonov, M.V. Rybin, A.N. Poddubny, Y.S. Kivshar. Nature Photonics 11, 543 (2017).

[12] S.A. Maier. Plasmonics: Fundamentals and Applications. Springer, NY (2007). 223 p.

[13] В.В. Климов. Наноплазмоника. Физматлит, М. (2010). $480 \mathrm{c}$.

[14] М. Борн, Э. Вольф. Основы оптики. Наука, М. (1970). $856 \mathrm{c}$. 